\title{
Recloser-fuse settings in distribution systems with optimizing multiple distributed generation considering technical aspects
}

\author{
Ahmed A. Elbaset ${ }^{1}$, AboulFotouh A. Mohamed ${ }^{2}$, Essam Abou El-Zahab ${ }^{3}$, M. A. Moustafa Hassan ${ }^{4}$ \\ ${ }^{1,2}$ Department of Electrical Power Engineering, The higher institute of engineering at ElShorouk City, Egypt \\ ${ }^{3,4}$ Department of Electrical Engineering, Cairo University, Egypt
}

\section{Article Info \\ Article history: \\ Received Apr 13, 2019 \\ Revised Jul 1, 2019 \\ Accepted Aug 29, 2019}

\section{Keywords:}

Distributed generation Optimum allocation Protection coordination Whale optimizer algorithm

\begin{abstract}
With the widespread of using distributed generation, the connection of DGs in the distribution system causes miscoordination between protective devices. This paper introduces the problems associated with recloser fuse miscoordination (RFM) in the presence of single and multiple DG in a radial distribution system. Two Multi objective optimization problems are presented. The first is based on technical impacts to determine the optimal size and location of DG considering system power loss reduction and enhancement the voltage profile with a certain constraints and the second is used for minimizing the operating time of all fuses and recloser with obtaining the optimum settings of fuse recloser coordination characteristics. Whale Optimizer algorithm (WOA) emulated RFM as an optimization problem. The performance of the proposed methodology is applied to the standard IEEE 33 node test system. The results show the robustness of the proposed algorithm for solving the RFM problem with achieving system power loss reduction and voltage profile enhancement.
\end{abstract}

Copyright (C) 2020 Institute of Advanced Engineering and Science. All rights reserved.

\section{Corresponding Author:}

Ahmed A. Elbaset, The higher institute of engineering, ElShorouk City, Cairo, Egypt.

Email: ahmed_baset2007@yahoo.com

\section{INTRODUCTION}

The main Nowadays, distributed generations are a vital part of electrical distribution systems [1]. The connection of DGs affects the power flow, voltage condition and the feeder losses. Therefore, proper sizes and location of DGs in the distribution system can attain some economical, technical and environmental benefit. Optimizing DG was investigated to improve voltage profile and reduce system power loss in distribution system as technical aspects [2-5]. For achieving economical and environmental aspects, renewable energy sources (RES) based DG were integrated to reduce energy emission and cost [6]. But with high penetration of DGs in the systems has negative impacts on the existing protection devices causing false tripping and miscoordination problem [7,8]. The typical electric networks are designed as a radial in nature. The main benefits of the radial systems are their lower cost and simplicity in protection system. These protection schemes comprise of main devices such as recloser and fuses. The coordination between Recloser and fuse are implemented based on the fuse-saving principles [9]. When the transient fault occurs in any branch of the network, fast operating mode of recloser permit the fault to self clear before melting the fuse. But when a permanent fault occurs, the fuse must operate before slow operating mode of recloser to avoid the interruption of loads between fuse and recloser. So, the protection coordination between all fuses and the recloser must be achieved to prevent the miscoordination between them. Thus, the Recloser in the radial system is imperative as 70 to $80 \%$ of all faults occurs in distribution system are transient in nature [10]. The short circuit current due to contribution of DGs increase the current pass through the fuse and permit fuse to operate before and faster than the recloser which leads to undesirable miscoordination [11]. 
The fault current is increased with increasing the penetration of DGs and the flows of the current are changed. As a result, due to the insertion of DG sources, the distribution scheme becomes active. Therefore, the DG can cause opposing effects to the current protection system, resulting in coordination failure and consequently reducing system reliability [12]. Diverse studies have been devoted in literature to mitigate the adverse effect of the miscoordination between recloser and fuse in the presence of DGs. A new adaptive approach with high penetration level of DG based PV source to keep the coordination between fuse and recloser without any changes in conventional protection settings of PV under worst fault condition was introduces in [13]. In [14], multi objective optimization approach is used to determine the minimum size of fault current limiter, optimal setting of time multiplier and pickup current settings of the devices to restore coordination of protection network with high penetration of DGs based synchronous machine besides economical solution for protection coordination with high capacities of DGs. In [15], the proposed approach is based on the connection of DG in the feeder via four switches and divides the feeder in a few protected zones to avoid the false tripping and to improve system reliability. In [16], An optimum setting of the recloser and the fuses using interior point method (IPM) based algorithm was introduced to remain proper coordination for multiple network conditions systems in the presence of FCLs with single/multiple DGs. Integrating DG in radial system can mitigate, activate the recloser feature and feeder relay with change in recloser curve by modifying the time multiplier setting using minimum ratio of recloser current to fusing current to insure that the coordination is achieved as illustrated in [17]. In [18], an adaptive setting of recloser is performed by adjustment the instantaneous over current device with the presence of different sizes of DG. The proposed methods in [19], [20] consider the maximum permissible capacity of DG connected in distribution system to prevent any protection miscoordination between fuse and recloser. Multi objective function investigated in [21] with maximum threshold value for DG penetration level in distribution system considering various technical impacts using different optimization techniques to avoid recloser -fuse miscoordination problem.

This paper presents a general framework to maintain the coordination between fuse and recloser in the distribution system with optimizing single/multiple DGs over a certain constraint considering system power loss reduction and voltage profile enhancement. For this purpose, a multi objective function based on WOA has been applied to find the optimum sizes and locations of single/multiple DGs to obtain the optimum settings of fuses and recloser which can coordinate properly with different sizes and location of DGs in the system with suitable time coordination interval.

The salient points of this paper can be summarized as follow:-

a) Introduce optimum setting of time multiplier setting for recloser fast and slow mode considering the operating times of all fuses with keeping the coordination time interval between them.

b) Providing Multi objective function related with single and multiple DG to maintain recloser-fuse coordination considering power loss reduction and voltage profile enhancement.

c) The simulation results of the presented WOA are compared with those obtained from other optimization algorithm such as Genetic algorithm (GA), Particle Swarm Optimization (PSO) and interior point Method (IPM) algorithms

d) The effectiveness of the proposed methodology is applied to the standard IEEE 33 node test system.

The rest of the paper is organized as follow: Section 2 introduces the problem formulation related with the setting characteristics of fuse and recloser, while Section 3 clarifies the whale optimizer algorithm, furthermore, Section 4 display the application and the simulation results, and finally, Section 5 demonstrates the conclusions. At the end of the paper, an updated list of references is attained.

\section{PROBLEM FORMULATION}

\subsection{Settings of Recloser and Fuse Characteristics}

To coordinate the recloser and fuse in distribution system, the fuse saving principle is established. The recloser close to the substation to protect feeder from any persistent fault and fuse are protect lateral feeder as illustrated in Figure 1. In case of temporary fault, fast mode of recloser is operate while fuse saving is adopted to prevent supply disconnect from consumers. During permanent fault, before the slow mode of recloser operate, the fuse must blow to avoid unnecessary operation of recloser as these disconnect great set of consumers. This operation is suitable for fuse recloser coordination to prevent unnecessary outages in the network [22]. The sequence of operation for fuse recloser coordination is depicted in Figure 2. 


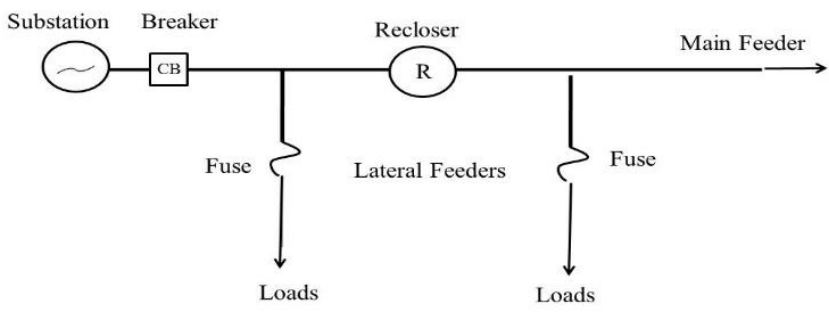

Figure 1. Location of recloser and fuse in distribution network

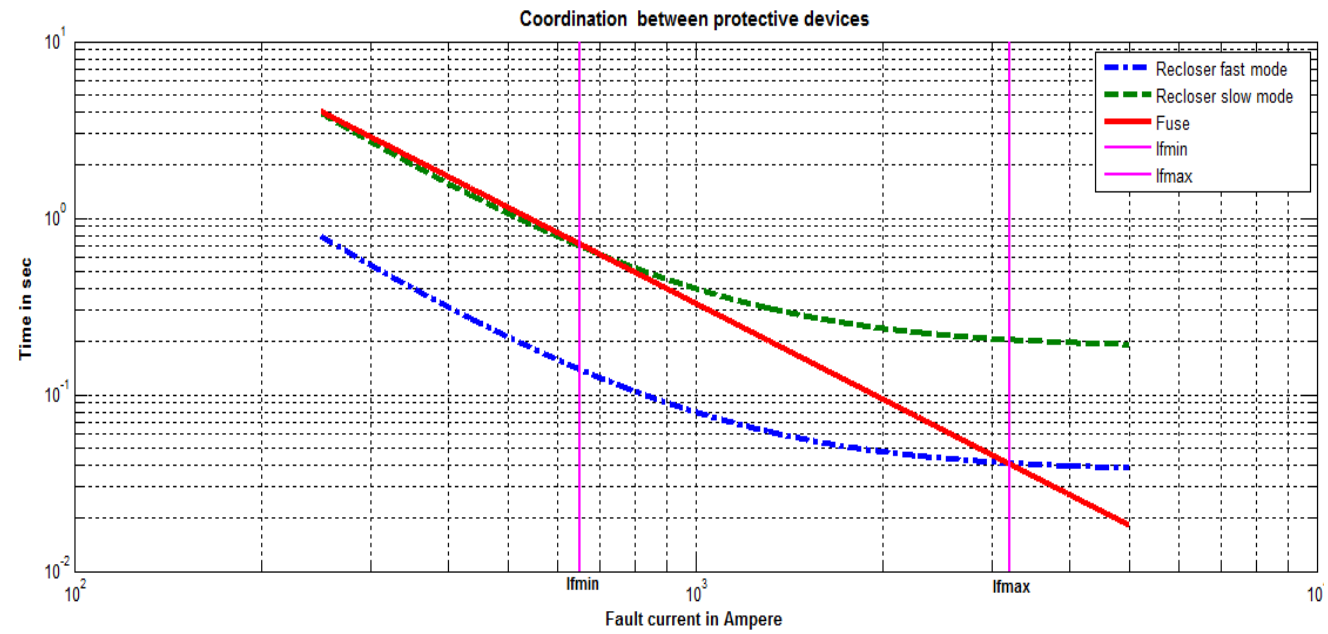

Figure 2. Coordination scheme between recloser and fuse

The recloser usually used as total backup protection for any permanent fault and primary for any momentary fault. The operating time for fast and slow mode of recloser is presented as the following equation [23].

$$
\begin{aligned}
& \mathrm{t}\left(\mathrm{I}_{\mathrm{f}}\right)=\operatorname{TMS}\left[\frac{\mathrm{A}}{\mathrm{M}^{\mathrm{P}-1}}+\mathrm{B}\right] \\
& \mathrm{I}_{\text {pickup }}=\mathrm{OLF} * \mathrm{I}_{\max }
\end{aligned}
$$

where

TMS Time multiplier setting

$\mathrm{T}\left(\mathrm{I}_{\mathrm{f}}\right) \quad$ Operating time of inverse-time overcurrent device

$\mathrm{M} \quad$ Ratio of I/Ipickup, (Ipickup is relay current set point)

A,B,P Constants for particular curve characteristics

OLF Over load factor

$I_{\max } \quad$ Max current through recloser

$\mathrm{I}_{\text {pickup }} \quad$ Pickup current setting of recloser

While fuses used as primary protection for any permanent fault. The common characteristic of fuse curve is illustrated as in [24].

$$
\log (\mathrm{tf})=\operatorname{alog}\left(\mathrm{I}_{\mathrm{ff}}\right)+b
$$

where
$t_{f} \quad$ operating time of fuse
$\mathrm{I}_{\mathrm{ff}} \quad$ fault current passing through fuse
a, b Fuse constant

From (3), when the value of constant $b$ is high, the operating time of fuse is high. 


\subsection{Coordination as an Optimization Problem}

The presence of DG in distribution network leads to difficulties in protection coordination and in technical impacts such as voltage profile and power loss. Thus the aim of this paper is to optimize the best size and location of DG to enhancing the voltage profile and reducing system power loss with the optimum settings of the fuses and recloser curve.

In this paper the DGs based on synchronous machine (DGSM) is considered as they can cause higher contribution for fault current and cause miscoordination between fuse and recloser [25]. The RFM emulated as an optimization problem. Thus, the multi objective function is developed to solve it and obtain optimum recloser-fuse coordination considering system power loss reduction and voltage profile enhancement.

\subsection{Objective Function Formulation And Constraints}

The objective function are classified in three parts such as optimal size of DG ( $\left.\mathrm{F}_{\mathrm{PDG}}\right)$, voltage profile index $\left(\mathrm{F}_{\mathrm{v}}\right)$, system power loss index $\left(\mathrm{F}_{\text {loss }}\right)[26]$.

a) Optimal sizes of DGs

The main objective is to find optimal sizes, number and location of DGs

$$
\text { Max FPDG, } \mathrm{F}_{\mathrm{PDG}}=\sum_{\mathrm{i}=1}^{\mathrm{nDG}} \mathrm{P}_{\mathrm{DG}}
$$

where $\mathrm{P}_{\mathrm{DG}}$ power injected from DGs at node $\mathrm{i}$ and $\mathrm{nDG}$ is number of $\mathrm{DG}$ connected.

b) Voltage profile index $\left(\mathrm{F}_{\mathrm{v}}\right)$

The value of voltage profile index $\mathrm{F}_{\mathrm{v}}$ depending on site and sizes of DGs and is used to reduce it from the reference voltage $\left(\mathrm{V}_{\text {ref }}\right)$ which is performed as

$$
\left.\operatorname{Min} F v, F_{v}=\frac{\sum_{i=1}^{\mathrm{n}}\left|\mathrm{v}_{\text {ref }}-\mathrm{v}_{\mathrm{i}}\right|}{\mathrm{v}_{\text {ref }}}\right)
$$

where $V_{i}$ is the Voltage magnitude at bus $i$ and $n$ is the number of buses.

c) Total system power loss index $\left(\mathrm{F}_{\text {loss }}\right)$

For radial distribution network, the real and reactive power loss indices $F_{\text {loss }}$ are factors used to determine the impact of DG in active and reactive power loss and depending on the location and size of DG and are expressed as

$$
\text { Min Floss }, \mathrm{F}_{\text {loss }}=\frac{\text { loss } \left.)_{\text {withoutDG }}-\text { loss }\right)_{\mathrm{DG}}}{\text { loss }_{\text {withoutDG }}}
$$

\begin{tabular}{|c|}
\hline $\begin{array}{l}\mathrm{F}_{\text {loss }} \\
\text { loss) } \\
\text { losithoutDG } \\
\text { DG }\end{array}$ \\
\hline
\end{tabular}

where

The multi objective function is used with different weight can be expressed as follow:

$$
\text { Min } \mathrm{OF}, \mathrm{OF}=\mathrm{w}_{1}\left(\frac{1}{\mathrm{~F}_{\mathrm{PDG}}}\right)+\mathrm{w}_{2}\left(\mathrm{~F}_{\text {loss }}+\mathrm{F}_{\mathrm{v}}\right)
$$

where $\mathrm{w}_{1}+\mathrm{w}_{2}=1$ are positive constant weight for all terms to achieve the performance calculation consider $\mathrm{w}_{1}=\mathrm{w}_{2}=0.5$ as all terms have the same importance with the same weight percentage.

The objective function (OF) in (7) is minimized with different operational constraints to satisfy the electrical requirements for distribution network. In this paper the optimization process are considered the losses and protection coordination as the main constraint.

\subsection{System constraints}

The total power loss reduction and voltage profile enhancement are the main constraints for the proposed RFM problem to achieve the technical impacts which are described as the following:

a) Power balance equality constraints

$$
\sum_{i=1}^{n} P_{D G i}=\sum_{i=1}^{n} P_{D i}+P_{\text {lossi }}
$$




$$
\sum_{i=1}^{n} Q_{D G i}=\sum_{i=1}^{n} Q_{D i}+Q_{\text {lossi }}
$$

where

$$
\begin{array}{ll}
P_{\text {lossi }}, Q_{\text {lossi }} & \text { Active and Reactive power loss at i-th buses } \\
P_{D G i}, Q_{D G i} & \text { DGs real power placed at bus i } \\
P_{D i}, Q_{D i} & \text { Load active and Reactive Power at node i }
\end{array}
$$

b) Voltage constrains

$$
\left|V_{i}^{\min }\right| \leq\left|V_{i}\right| \leq\left|V_{i}^{\max }\right|
$$

The voltage limit for buses between (0.95 -1.05 pu).

\subsection{Optimum Fuse-Recloser Coordination in the Presence of DGs Unit}

The connection of DG in distribution system changes the direction of fault currents across each protection devices. So the coordination settings between all fuses and recloser are complicated especially in case of connecting multiple DG units in distribution systems. To achieve the correct operation between recloser and fuses in the presence of single/multiple DGs units, an evolutionary optimization technique is formulated with multiple objective functions with the same settings at certain coordination margin with and without DG. Therefore, the objective function of the optimization problem is established to minimize the operating times of all fuses and recloser with certain minimum coordination time interval between them.

$$
\text { Min } \mathrm{OF}, \mathrm{OF}=\sum_{\mathrm{j}=1}^{\mathrm{n}} \mathrm{t}_{\mathrm{rec}}+\sum_{\mathrm{k}=1}^{\mathrm{nfuse}} \mathrm{t}_{\text {fuse }}
$$

subjected to the following constraints:

$$
\begin{aligned}
& t_{\text {fuse }}-t_{\text {recfast }} \geq M R C M / 2(12) \\
& t_{\text {recslow }}-t_{\text {fuse }} \geq M R C M / 2(13) \\
& t_{\text {recslow }}-t_{\text {recfast }} \geq M R C M(14) \\
& t_{\text {fuse }(\mathrm{k}+1)}-t_{\text {fuse }(\mathrm{k})} \geq M F C M(15) \\
& \text { TMS }_{\text {min }} \leq \text { TMS } \leq \mathrm{TMS}_{\max }(16)
\end{aligned}
$$

where

$$
\begin{array}{ll}
\text { nfuse } & \text { Total number of fuses } \\
t_{\text {recfast }} & \text { Operating time of fast recloser } \\
t_{\text {recslow }} & \text { Operating time of slow recloser } \\
\text { MFCM } & \text { Min Fuse coordination margin } \\
\text { MRCM } & \text { Min. Recloser coordination margin } \\
\text { TMS }_{\min } \text { and TMS } & \text { Min. and Max.Time multiplier setting }
\end{array}
$$

The coordination between fuse and recloser is classified based on the fault location and associated with the capacity and location of DG. For single DG connected at any location in the system, the fault current seen by recloser and fuse are defined as follow:

$$
\begin{aligned}
& \text { IRecloser = I substation } \\
& \text { I Fuse = I substation + IDG }
\end{aligned}
$$

In this case, a high fault current detected by the fuse more than recloser. Thus, to avoid RFM problem, the fault current through the fuse is limited to a threshold value and the constraint can be written as follows.

$$
\mathrm{I}_{\text {Fuse }} \leq \mathrm{I}_{\text {Fuse-margin }} \text { and } I_{\text {Fuse-margin }}=10^{\left.\left(\log \left(t_{\text {recfast }}\right)-b\right) / a\right)}
$$

The optimization algorithm search the optimal size and location of single and multiple DG units to satisfying the technical constraints using (8), (9) and (10), while the operating times of all fuses and recloser is minimized at this optimizing values of DGs obtained from first objective function and satisfying all constraints illustrated from (12) to (19).

The steps of the solution procedure to obtain optimum Recloser fuse settings are as follows:

Step1: Carry out base case load flow and short-circuit program

Step2: Calculate the fault currents via recloser and fuses.

Step3: Select the pickup current of recloser using (2) 
Step4: Select currents require in the optimum recloser fuse coordination form.

Step5: Set the Parameter of Whale optimizer algorithm.

Step6: Apply WOA program to obtain the optimum size and location of single/multiple DG added at bus location and go to Step (1)

Step7: Select the faulted bus and go to step (2)

Step8: Evaluate objective function using (4) and (8).

Step9: Obtain optimum setting of TMS for recloser and fuses constants $(a, b)$.

Step10: Check all constraint and go to step (6)

Step11: Calculate optimum size and location to attain optimum recloser fuse coordination settings and print the results.

The flow chart of the proposed algorithm is revealed in Figure 3.

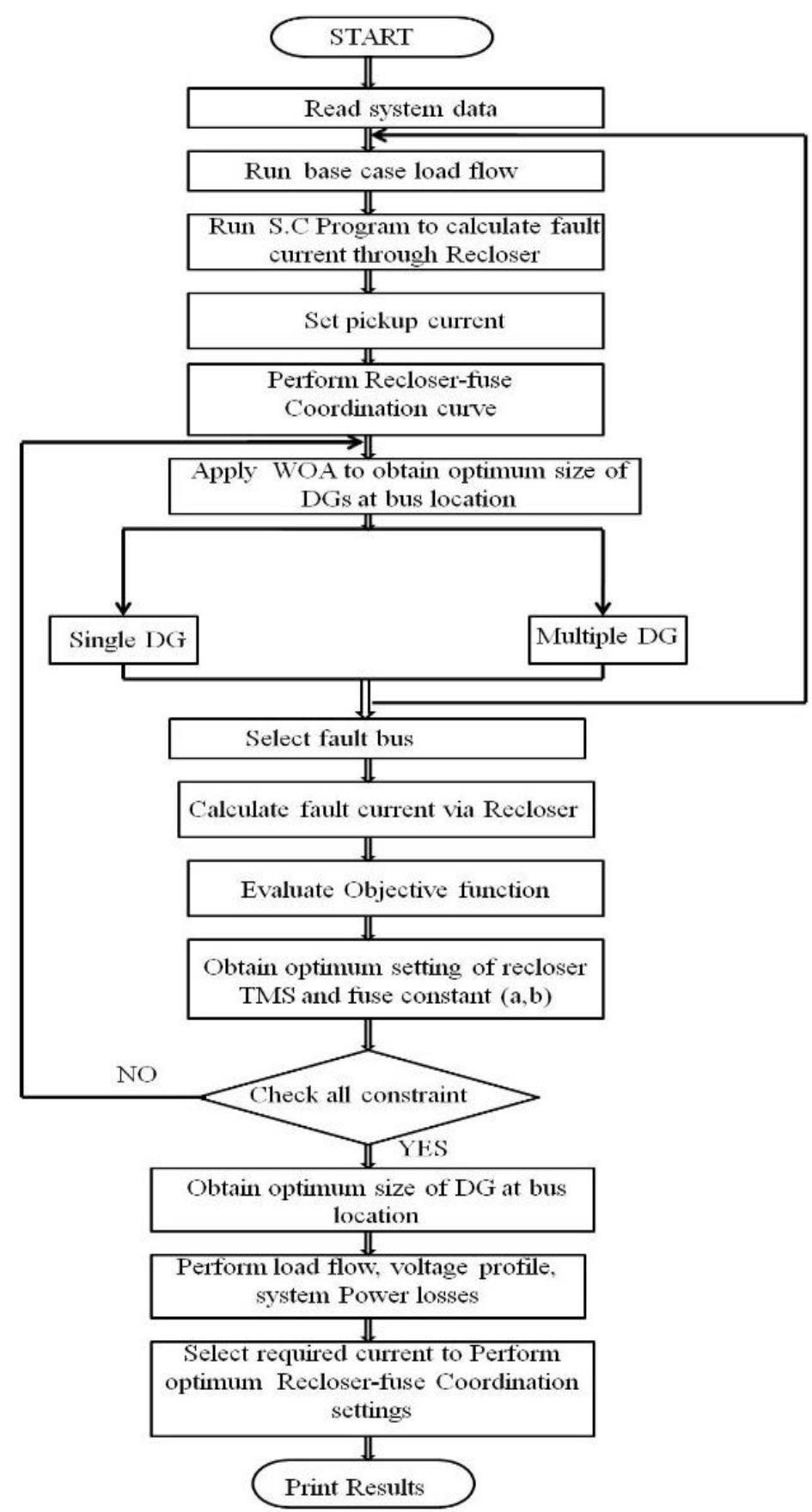

Figure 3. Computational Procedure for proposed techniques 


\section{WHALE OPTIMIZER ALGORITHM}

When DGs are connected to the distribution feeder network, the fault current level is increased and RFM are occurs. Therefore, the coordination of protection scheme is formulated as an optimization problem to insure the sequence of operation is unchanged; thus, an Evolutionary Technique using Whale Optimizer Algorithm (WOA) is implemented to solve this problem.

WOA is a nature-stimulated meta-heuristic optimization technique proposed in [27]. Population based WOA has the ability to keep away from local optima and find a global optimal result without any necessary replacement in methodology for solving different constrains or unconstraint optimization difficulties. WOA decreases the computational times for highly complicated problems. WOA emulate the behavior of different hunting humpback whales by encircling the victim which update its position to get the optimum solution based on exploitation phase and exploration phase. The mathematical procedures for WOA are illustrated in [27]. The flow chart of the suggested technique is illustrated in Figure 4.

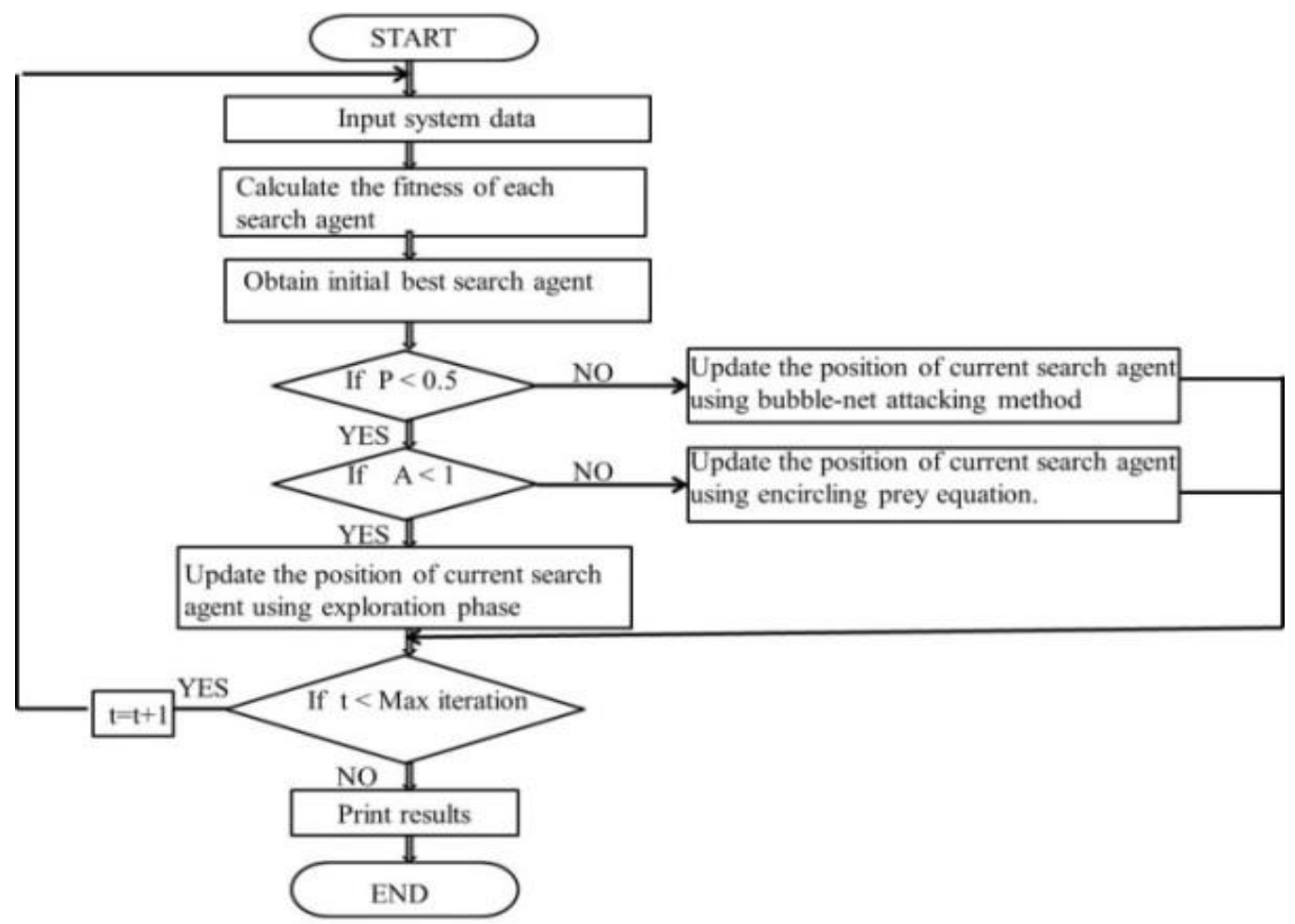

Figure 4. Flow chart of the Suggested WOA

\section{APPLICATION AND SIMULATION RESULT}

The Simulation studies are performed on a standard IEEE 33 node test system [28]. The short circuit programs are developed according to Z-bus method to compute the maximum fault currents passing through each protective devices of the network. A load flow algorithm based on Bus-Injection to Branch-Current (BIBC) and Branch-Current to Bus voltage (BCBV) matrices is designed to compute the current setting of each protective element for radial distribution systems [29].

\subsection{IEEE 33 Node Test System}

The single line diagram of the test system is revealed in Figure 5 . The operating voltage is $12.66 \mathrm{kV}$ feeding 17 commercial, 8 residential and 7 industrial loads. At the substation the short circuit level is supposed as $100 \mathrm{MVA}$. The total active and reactive load power in this system are $3.72 \mathrm{MW}$ and 2.3 MVAR respectively [28]. The initial loss power in this system is $0.2022 \mathrm{MW}$ and the lowest bus bar voltage is 0.9133 pu at node 18 .

The proposed methodology is implemented in MATLAB R2013a to calculate the optimum sizes and location of DGs along the feeder to avoid the false tripping and miscoordination between fuse and recloser with minimum power loss and improve voltage profile. The short circuit program is executed based on the Zbus method with and without the presence of DGs. 
The test system shown in Figure 5 comprises one recloser and six fuses. Recloser is placed at the main feeders to protect it from temporary fault and also used as a backup protection for any persistent fault in the network. Fuses are placed downstream the recloser after each node to give a primary protection against persistent faults in each branch of the network. All fuses are located at each branch instead of lateral feeder to formulate a complete protection against any persistent fault in the main feeder. Thus, a total of proper seven sequences of the protective devices are achieved to avoid RFM problem for any fault in the system. The correct sequences are illustrated in Table 1.

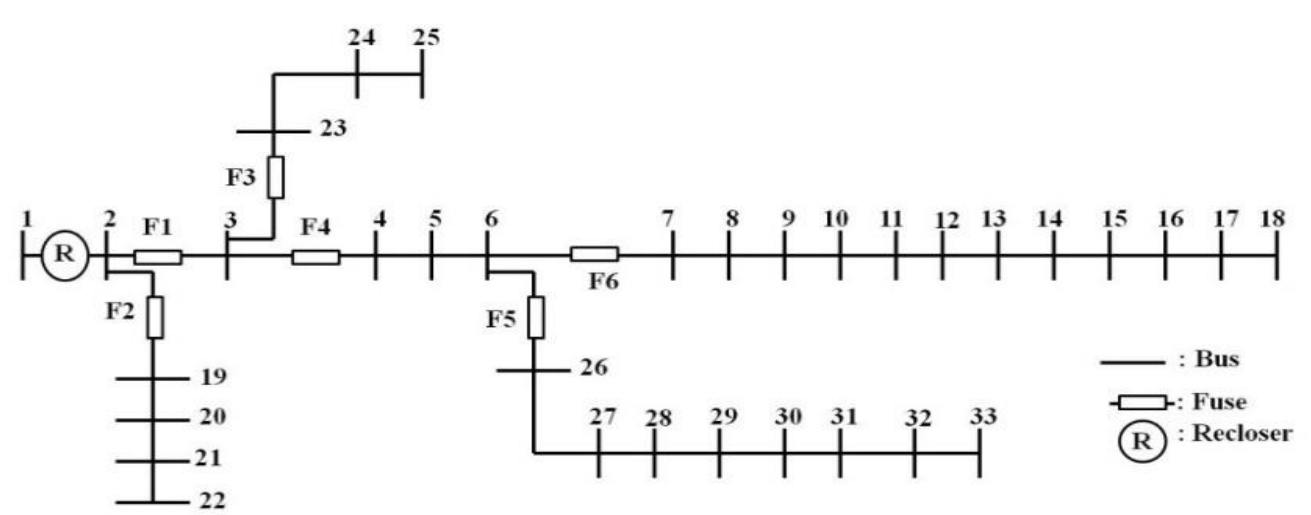

Figure 5. Single line diagram for 33-node test system

Table 1. Operating Sequences for the Protective Devices for Any Fault in the System

\begin{tabular}{cc}
\hline Seq. Number & Sequences Operation \\
\hline 1 & $\mathrm{R}_{\mathrm{fm}}-\mathrm{R}_{\mathrm{sm}}$ \\
2 & $\mathrm{R}_{\mathrm{fm}}-\mathrm{F}_{1}-\mathrm{R}_{\mathrm{sm}}$ \\
3 & $\mathrm{R}_{\mathrm{fm}}-\mathrm{F}_{2}-\mathrm{R}_{\mathrm{sm}}$ \\
4 & $\mathrm{R}_{\mathrm{fm}}-\mathrm{F}_{3}-\mathrm{F}_{1}-\mathrm{R}_{\mathrm{sm}}$ \\
5 & $\mathrm{R}_{\mathrm{fm}}-\mathrm{F}_{4}-\mathrm{F}_{1}-\mathrm{R}_{\mathrm{sm}}$ \\
6 & $\mathrm{R}_{\mathrm{fm}}-\mathrm{F}_{5}-\mathrm{F}_{4}-\mathrm{F}_{1}-\mathrm{R}_{\mathrm{sm}}$ \\
7 & $\mathrm{R}_{\mathrm{fm}}-\mathrm{F}_{6}-\mathrm{F}_{4}-\mathrm{F}_{1}-\mathrm{R}_{\mathrm{sm}}$ \\
\hline
\end{tabular}

\subsection{Simulation Results}

The optimum settings of TMSs for recloser and constants for all the fuses obtained using the proposed approach for the system with and without considering DG is presented according to some constraint to avoid RFM problem in addition system power loss reduction and voltage profile improvement. Multi-objective function is introduced to determine the location and size of DGs in the distribution system to minimize the total system loss and enhance voltage profile with maintaining coordination between recloser and fuse. The optimization process considers the protective device coordination, voltage profile and line loss as main constraint to achieve all proposed objective function. The proper settings of TMS parameter regard as recloser to operate for one fast trip to self clear the fault and operate as primary protection while one delayed trip for fuses are considered to operate as backup protection.

The values of minimum and maximum TMS for optimum coordination have been chosen between 0.2 and 5, respectively. The over load factor for the recloser set to 1.5 [30]. The coordination margin MFCM between the fuses have been chosen as $100 \mathrm{msec}$, while the coordination margin between recloser MRCM has been chosen as $200 \mathrm{msec}$. with these settings; the protective devices are completely coordinated.

Simulations results are performed in three different scenarios:

a) Without installing DG

b) With installing only one DG

c) With installing Multiple DG

The two scenarios (ii) and (iii) are implemented by applying the proposed optimization technique to achieve all the objective functions.

\subsubsection{Without Installing DG}

The output of the three-phase short circuit at different fault location without any DG is revealed in Figure 6. The operation setting of Recloser is based on extremely inverse characteristics that have the values 
of $\mathrm{A}, \mathrm{B}, \mathrm{P}$ of $28.2,0.1217$, and 2 respectively as in [23]. The value of constant (a) for all the fuses has been considered to be the same as all fuses in the system are the same type [30]. The computational procedures for the conventional coordination between fuse and recloser are illustrated in [31]. With the optimum settings of TMS for recloser and constants of all fuses without installing DG, the coordination is obtained using time current characteristic as revealed in Figure 7.

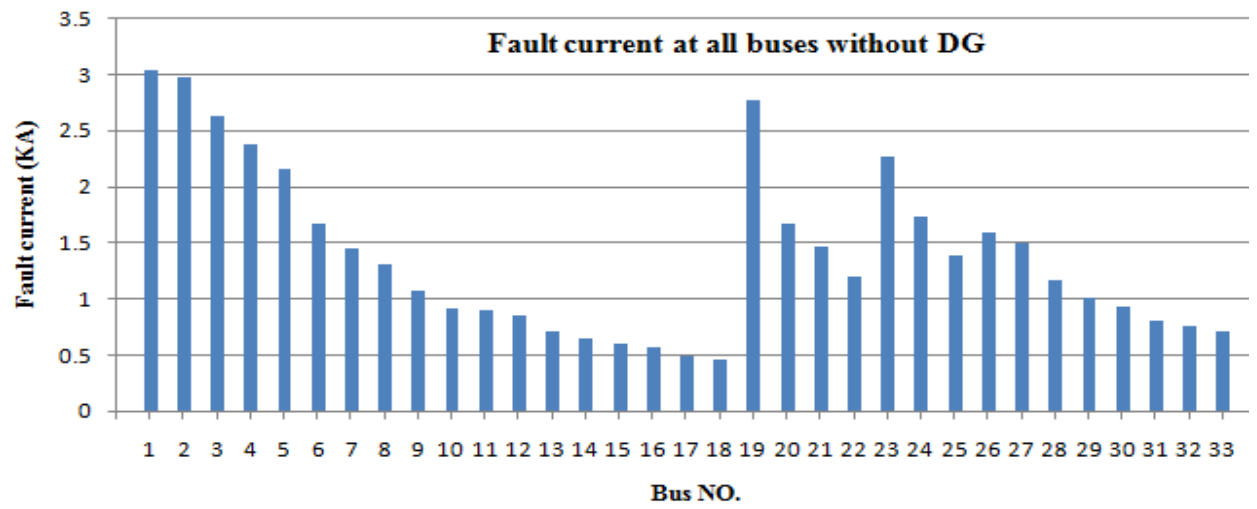

Figure 6. Fault current of the test system in different fault location without DG

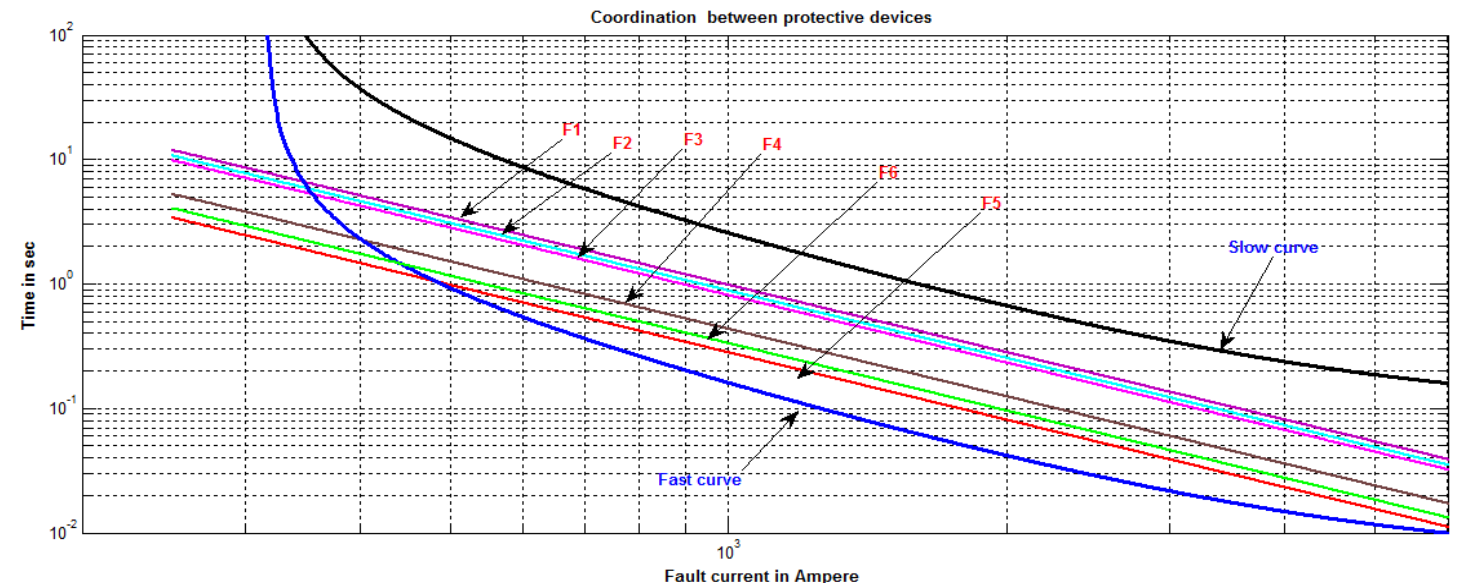

Figure 7. Time current characteristic curve of all protective devices

As in (3), with high value of constant $b$ the operating time is high. From Table 2 the value of constant $\mathrm{b}$ for fuse 4 (F4) is higher than the value for fuses 7 (F5) and 8 (F6), while that value for fuse 2 (F2) is higher than that for fuses $3(\mathrm{~F} 43)$ and $4(\mathrm{~F} 4)$. Consequently, fuse 2 (F2) is higher than fuse 3 (F3). And thus, Fuse 4 (F4) is backup protection for fuses 5 (F5) and 6 (F6) and fuse 2 (F2) is backup protection for fuses 3 (F3) and 4 (F4). From Figure 7, the characteristic of the optimum values of all fuses are located between the operating times of recloser. Thus the sequences of operation in Table 2 are kept unchanged.

Table 2. Optimum Settings of Protection Scheme without DG

\begin{tabular}{ccccc}
\hline \multicolumn{2}{c}{ Recloser } & \multicolumn{3}{c}{ Fuses } \\
Fast mode & Slow mode & Fuse No & Fuse Constant (a) & Fuse Constant (b) \\
\hline & & F1 & -1.8 & 5.3919 \\
Ip=320A & Ip=320A & F2 & -1.8 & 5.3465 \\
TMS=0.3 & TMS=3.5125 & F3 & -1.8 & 5.3090 \\
& & F5 & -1.8 & 5.0378 \\
& & F6 & -1.8 & 4.8489 \\
& & & -1.8 & 4.9233 \\
\hline
\end{tabular}




\subsubsection{With Installing Only One DG}

The DG units in this study are considered to be synchronous-type generators as they can cause miscoordination between recloser and fuse due to high contribution to fault currents [25]. All synchronous machine used are operates at unity power factor. The optimum setting of TMS for the recloser and all fuse constants have been considered in the presence of single and multiple DG units in the application of the presented methodology.

From the result the optimum size and location of DG that satisfy the coordination constraints between fuse and recloser for protection system is presented at bus 7 with rated power of $2.5434 \mathrm{MW}$ and is operated at unity power factor. The short circuit capacity of DG is 25MVA.

The results of the optimal capacity of single DG at each bus location for the test system with considering technical impacts and protection coordination constraint are illustrated in Table 3. The optimizing value of DG is integrated to insure that when the fault occurs in any lateral feeders, the proper coordination between fuse and recloser is achieved.

In Table 3, the lowest value of power losses occurs with DG located at bus 7 with minimum power loss of $0.1037 \mathrm{MW}$ and reactive power loss of $0.0746 \mathrm{MVAR}$ compared to other value due to including the protection coordination constraint in the multi-objective function.

The variation of voltage profile for the test system with and without the presence of DG unit using the presented algorithm is depicted in Figure 8. The three-phase short circuit at various locations with single DG unit located at bus 7 is revealed in Figure 9.

The time-current characteristic curves of the recloser and the fuses using their optimum coordination results obtained are depicted in Figure 10. Optimum settings of protection scheme in the presence of single DG unit shown in Table 4.

Table 3. Optimum Size of Single DG Achieving Protection Coordination

\begin{tabular}{ccc}
\hline & Without DG & With one DG \\
\hline DG location & ----- & 7 \\
Size (MW) & ----- & 2.5434 \\
Loss (MW) & 0.2022 & 0.1037 \\
Qloss (MVAR) & 0.1348 & 0.0746 \\
Min.Voltage (pu) & 0.9133 & 0.9512 \\
Ifmax (KA) & 3.0386 & 3.254 \\
\hline
\end{tabular}

Table 4. Optimum Settings of Protection Scheme in the Presence of Single DG Unit

\begin{tabular}{ccccc}
\hline \multicolumn{2}{c}{ Recloser } & \multicolumn{3}{c}{ Fuses } \\
Fast mode & Slow mode & Fuse No & Fuse Constant (a) & Fuse Constant (b) \\
\hline & & F1 & -1.8 & 5.4912 \\
Ip=320A & Ip=320A & F2 & -1.8 & 5.4723 \\
TMS=0.3 & TMS=3.5220 & F4 & -1.8 & 5.4439 \\
& & F5 & -1.8 & 5.3653 \\
& & F6 & -1.8 & 5.1205 \\
& & &
\end{tabular}

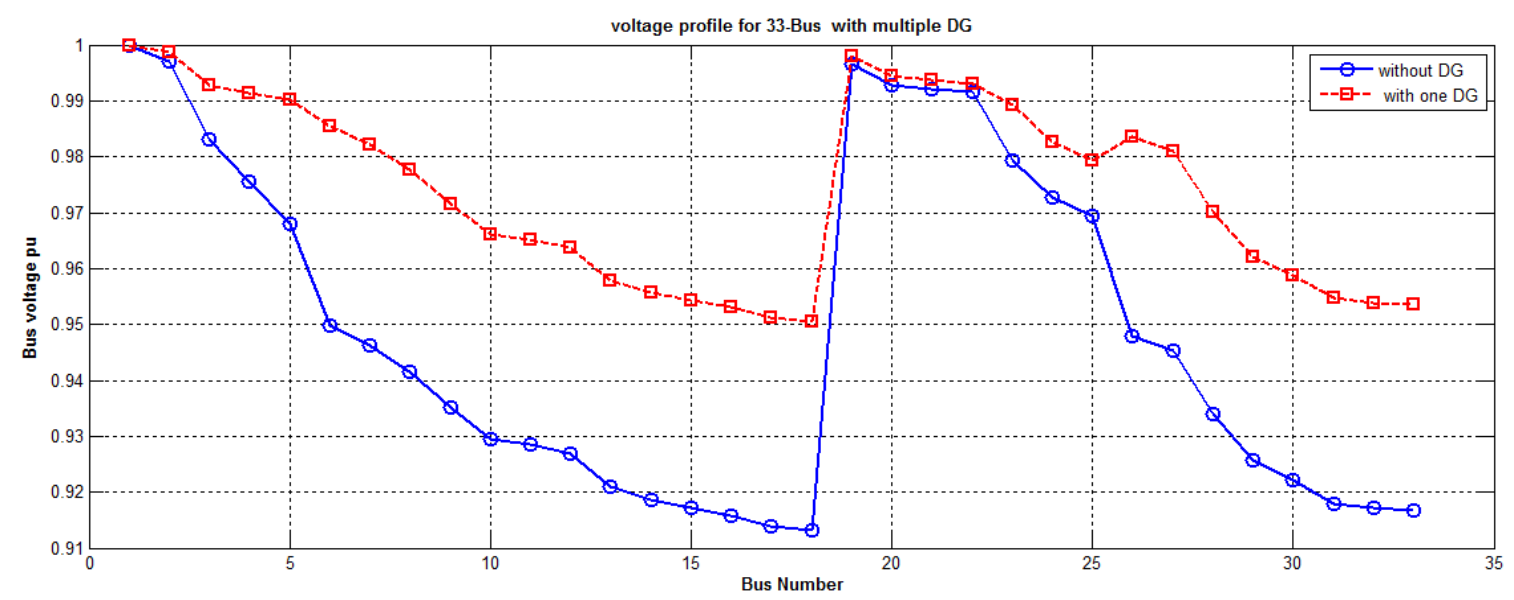

Figure 8. Voltage profile without and with only one DG located @ bus 7 


\section{Fault current at all buses with one DG}

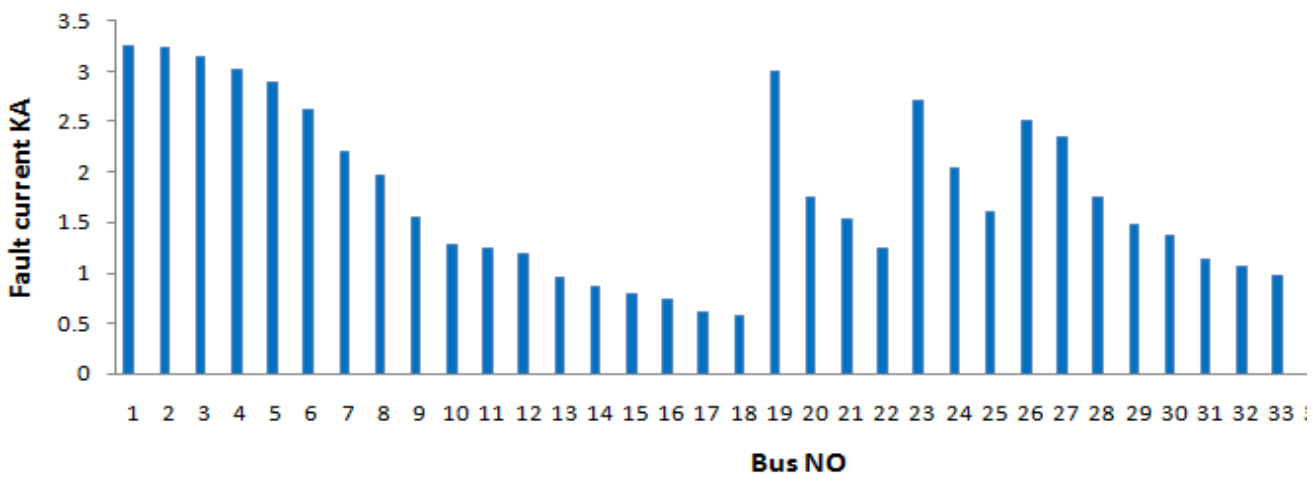

Figure 9. Fault current of the test system in different location with single DG unit

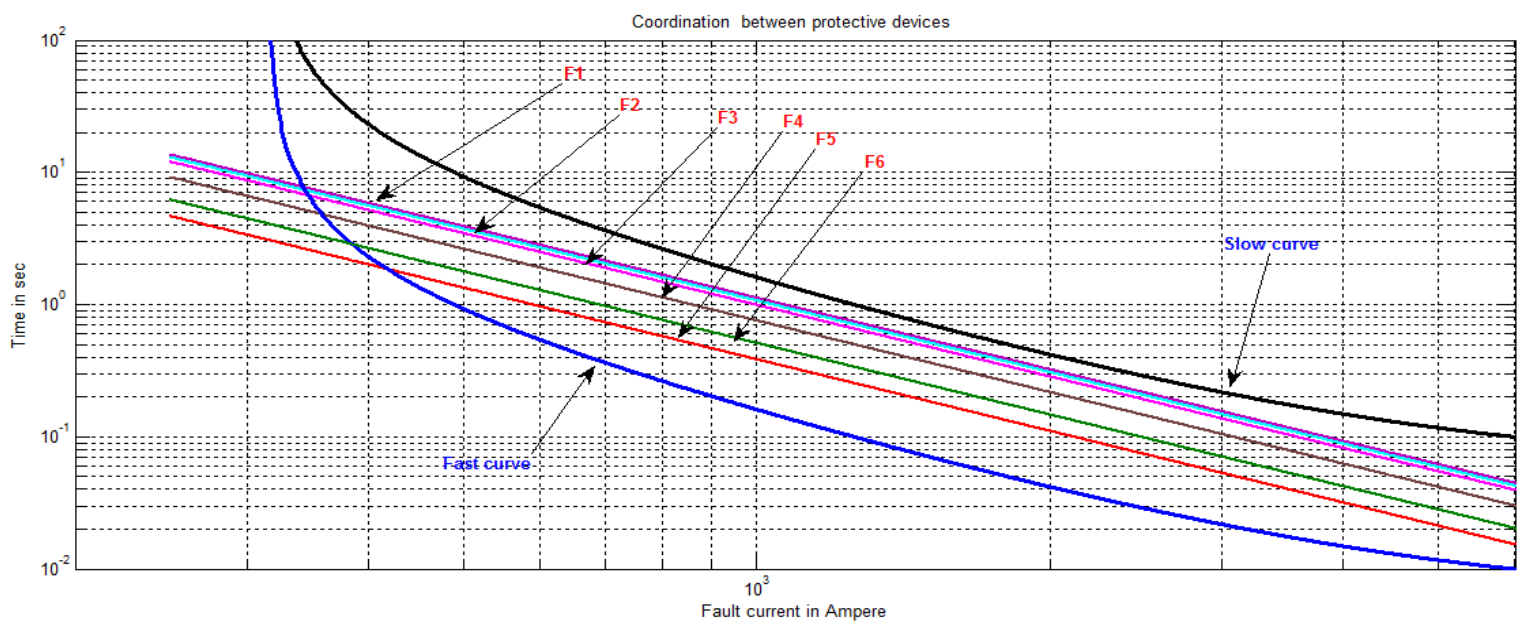

Figure 10. Time current characteristic of all protective devices after adding one DG

\subsubsection{With Installing Multiple DG}

From the result the optimum sizes and location of DG that achieve all objective function is presented at buses 7, 16 and 25 with rated output power of $1.6923 \mathrm{MW}, 0.4523 \mathrm{MW}$ and $0.5361 \mathrm{MW}$, respectively, with unity power factor. The optimum sizes and locations of the DGs units that achieve the technical impacts and the coordination margin between recloser and fuse are depicted in Table 5.

Table 5 shows that after inserting one DG unit, the reduction in system power loss is reduced to 48.7\% compared with that without DG units and the minimum bus voltage is improved. The system power loss is reduced with adding two DG and with three DG units to $54 \%$ and $57.27 \%$, respectively. DG can cause enhancement of system voltage condition. However, the short circuit level is increased with increasing the number of DG units.

The variation of voltage profile for the test system before and after adding multiple values of DG units using the applied technique is depicted in Figure11. The short circuit current at each bus locations with multiple DG units is revealed in Figure 12.

Table 5. Optimal Allocation of DG Achieve Protection Coordination Along the System

\begin{tabular}{|c|c|c|c|c|c|c|c|}
\hline & Without DG & With one DG & \multicolumn{2}{|c|}{ With Two DG } & \multicolumn{3}{|c|}{ With Multiple DG unit } \\
\hline Bus location & ----- & 7 & 7 & 16 & 7 & 16 & 25 \\
\hline Size (MW) & ------ & 2.5434 & 1.8979 & 0.5196 & 1.6923 & 0.4523 & 0.5361 \\
\hline Loss (MW) & 0.2022 & 0.1037 & \multicolumn{2}{|c|}{0.0930} & \multicolumn{3}{|c|}{0.0864} \\
\hline Qloss (MVAR) & 0.1348 & 0.0746 & \multicolumn{2}{|c|}{0.0658} & \multicolumn{3}{|c|}{0.0612} \\
\hline Min.Voltage (pu) & 0.9133 & 0.9512 & \multicolumn{2}{|c|}{0.9601} & \multicolumn{3}{|c|}{0.9622} \\
\hline $\mathrm{I}_{\text {fmax }}(\mathrm{KA})$ & 3.0386 & 3.254 & \multicolumn{2}{|c|}{3.287} & \multicolumn{3}{|c|}{3.406} \\
\hline
\end{tabular}

Recloser-fuse settings in distribution systems with optimizing multiple distributed... (Ahmed A. Elbaset) 


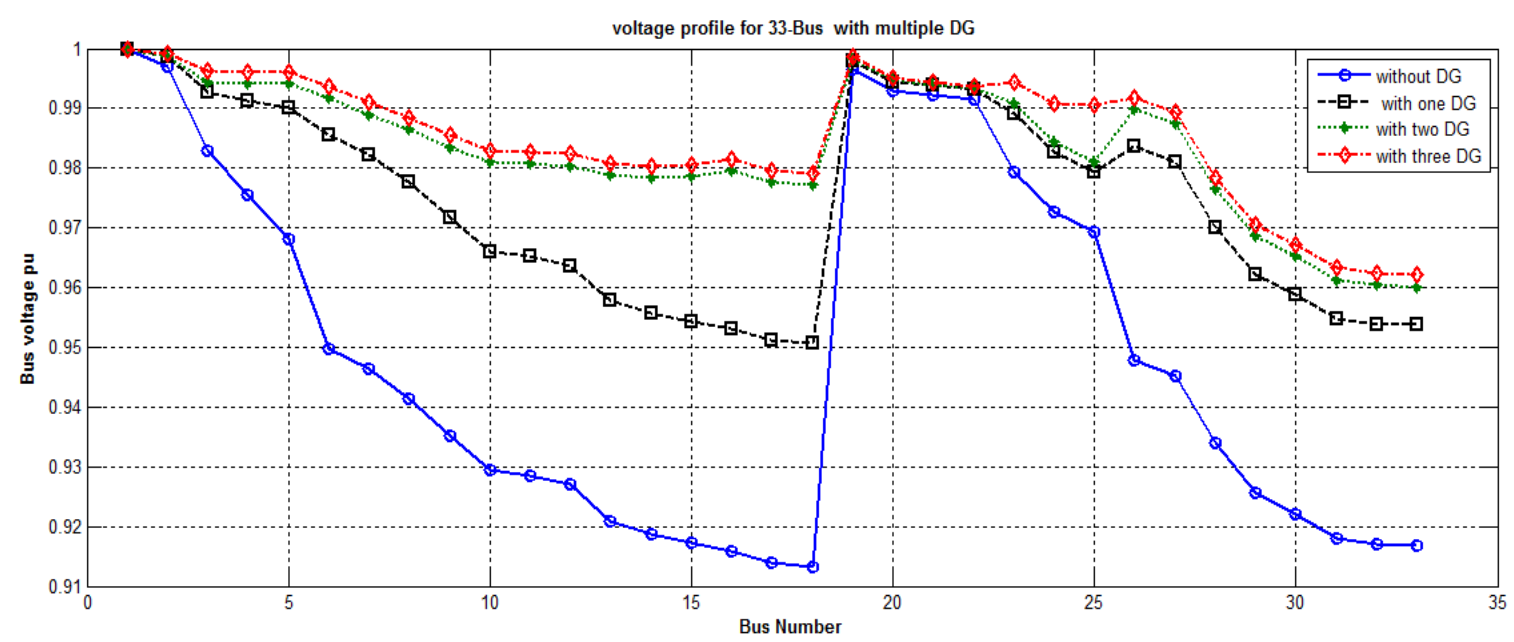

Figure 11. Variation of Voltage profile without and with multiple DG units

\section{Fault current with multiple DG units}

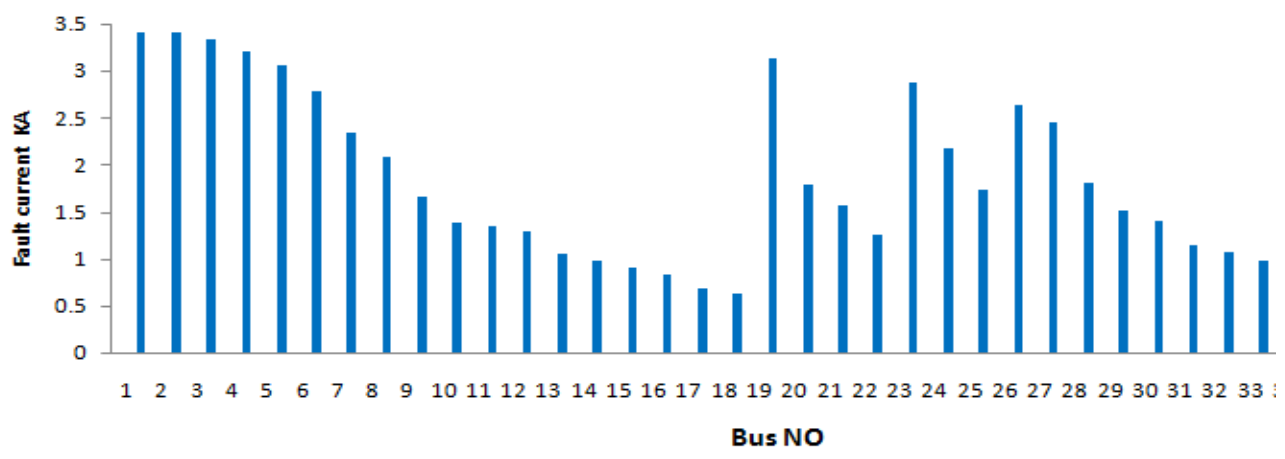

Figure 12. Fault current of the test system in different location with Multiple DG

From Table 6, it is observed that in the presence of single DG and multiple DGs, the fuse constant $\mathrm{b}$ for fuse 6 (F6) is higher than that for fuses $7(\mathrm{~F} 7)$ and $8(\mathrm{~F} 8)$, while the constant $\mathrm{b}$ for fuse 3 (F3)is higher than those for fuse 4 (F4) and 5 (F5) and the constant b for fuse 2 (F2) is higher than those for fuse3 (F3). Thus, fuse (F6) provides backup protection to fuses 4 (F5) and 5 (F5) while fuse (F6) provides backup protection to fuses $7(\mathrm{~F} 7)$ and $8(\mathrm{~F} 8)$ and then fuse 2(F2) provides backup protection to fuse3 (F3). Further, from Figure 10 and Figure 13, it is observed that the optimum coordinated characteristics of the fuses are located between the operating times for fast and slow modes of operation for the recloser. Therefore, the operating sequences depicted in Table 1 are properly achieved.

Table 6. Optimum Settings of Protection Scheme in the Presence of Multiple DG

\begin{tabular}{ccccc}
\hline \multicolumn{2}{c}{ Recloser } & \multicolumn{3}{c}{ Fuses } \\
\hline Fast mode & Slow mode & Fuse No & Fuse Constant (a) & Fuse Constant (b ) \\
& & F1 & -1.8 & 5.4500 \\
& & F2 & -1.8 & 5.4296 \\
Ip=320A & Ip=320A & F3 & -1.8 & 5.3961 \\
TMS=0.3 & TMS=3.5295 & F4 & -1.8 & 5.2783 \\
& & F5 & -1.8 & 4.9846 \\
& & F6 & -1.8 & 5.1080 \\
\hline
\end{tabular}




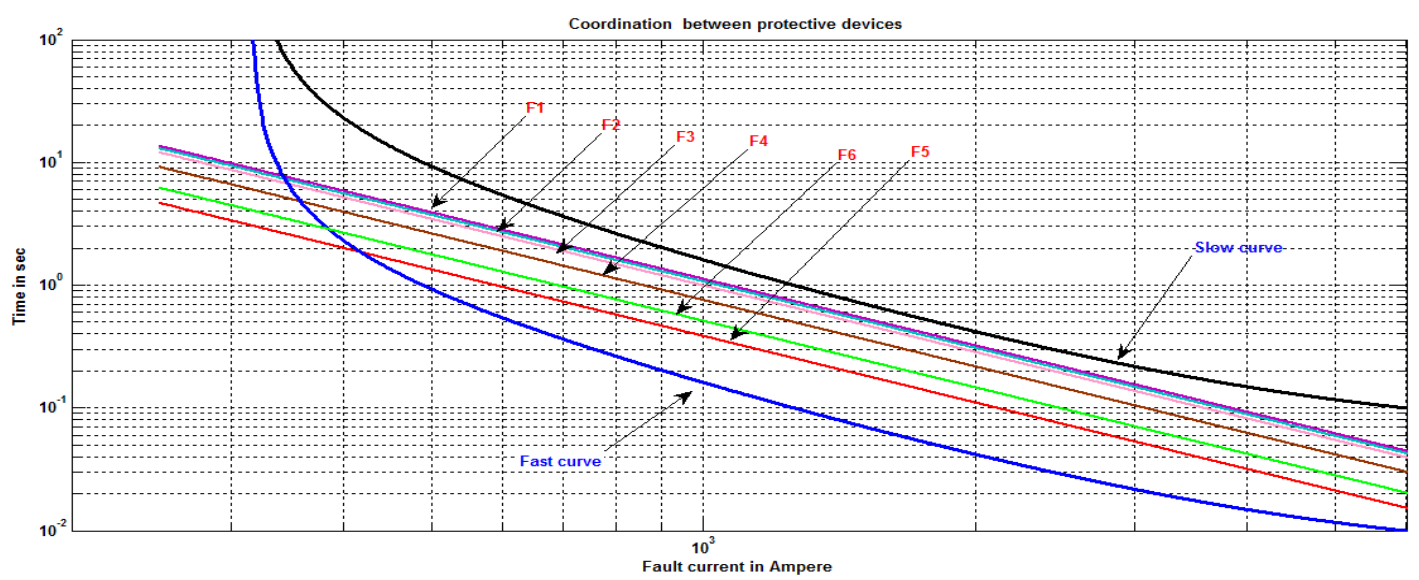

Figure 13. Time current characteristic of all protective devices after adding multiple DG

\subsection{Comparison Results between Proposed and Other Methodology}

Table 7 shows the comparison between the proposed methodology and other methods called GA, PSO and IPM. The optimum coordination between recloser and fuse using all methods is obtained in case of installing single and multiple DG units. From Table 7, the results obtained from WOA has the total minimum operating time compared with that obtained from GA, PSO and IPM in case of installing single and multiple DG units.

Thus the proposed WO algorithm has the superiority in solving RFM problem with maximum technical impacts such as minimizing power loss and improving system voltage when compared with GA, PSO and IPM.

Table 7. Comparison between Different Optimization Methods

\begin{tabular}{|c|c|c|c|c|c|c|c|c|c|c|c|}
\hline & \multirow[b]{2}{*}{ Methods } & \multicolumn{2}{|c|}{ Recloser TMS } & \multirow{2}{*}{$\begin{array}{c}\text { Fuse } \\
\text { const. (a) }\end{array}$} & \multirow[b]{2}{*}{$\mathrm{F} 1$} & \multicolumn{4}{|c|}{ Fuse const.(b) } & \multirow[b]{2}{*}{ F6 } & \multirow{2}{*}{$\begin{array}{c}\text { Total } \\
\text { Operating } \\
\text { time (sec) }\end{array}$} \\
\hline & & Slow & Fast & & & $\mathrm{F} 2$ & $\mathrm{~F} 3$ & $\mathrm{~F} 4$ & F5 & & \\
\hline GA & Single DG & 0.5 & 9.253 & -1.801 & 14.937 & 15.526 & 14.256 & 15.326 & 13.931 & 15.126 & 13.1927 \\
\hline \multirow{2}{*}{ PSO } & Single DG & 0.5 & 7.717 & -2.183 & 18.261 & 17.949 & 17.698 & 17.751 & 17.163 & 17.541 & 11.5539 \\
\hline & Multiple DG & 0.5 & 7.638 & -2.102 & 17.623 & 17.066 & 16.751 & 16.844 & 15.463 & 16.633 & 12.3626 \\
\hline IPM & Single DG & 0.5 & 7.632 & -2.179 & 18.134 & 17.912 & 17.349 & 17.712 & 16.836 & 17.512 & 10.3660 \\
\hline \multirow{2}{*}{ WOA } & Single DG & 0.3 & 3.522 & -1.800 & 5.4912 & 5.4723 & 5.4439 & 5.3653 & 5.1205 & 5.2159 & 7.95780 \\
\hline & Multiple DG & 0.3 & 3.5295 & -1.800 & 5.4500 & 5.4296 & 5.3961 & 5.2783 & 4.9846 & 5.1080 & 8.00150 \\
\hline
\end{tabular}

\section{CONCLUSION}

This paper introduces two multi objective optimization problems. The first associated with RFM problem to minimize the sum of operating time of all fuses and recloser and the second is consider many technical benefits such as voltage profile enhancement and system power loss reduction. The single set is sufficient to maintain the correct operation of recloser and fuses with and without the presence of a single and multiple DGs in the distribution system. The obtained results reveal that the optimizing value of DG units is maintained the coordination between recloser and fuses with suitable constraint. Whale optimizer algorithm is applied to compute the optimal size and location of single/multiple DG to enhance voltage profile and minimize power loss with some constraints to avoid RFM problem. Simulation results approved that the robustness of the WOA compared to the other techniques for solving RFM problem with minimizing power loss and enhancing system voltage.

\section{REFERENCES}

[1] Ackermann, T., Anderson, G., Söder, L. Distributed generation: a definition. Electric Power Systems Research.2001;57 (3) : 195-204.

[2] A.Y. Abdelaziz, S.F. Mekhamer, R.H. Shehata. Solution of distributed generation allocation problem using a novel method. Indonesian Journal of Electrical Engineering and Computer Science. 2019,10(2): 554-564. 
[3] Muhamad Najib Kamarudin, Tengku Juhana Tengku Hashim, AbdulHamid Musa. Optimal sizing and location of distributed generation for loss minimization using firefly algorithm. Indonesian Journal of Electrical Engineering and Computer Science.2019,14(1): 421-427.

[4] Oladepo Olatunde, Hasimah Abdul Rahman. Allocation of distributed generation and capacitor banks in distribution system. Indonesian Journal of Electrical Engineering and Computer Science. 2019,13(2): 437-446.

[5] Mohamed I. Mossad, Ahmed Mohamed Abd Elbaset, M G Ashmawy. Optimal allocation of distributed generation considering enhancement of distribution system performance using artificial intelligence. Seventeenth International Middle East Power Systems Conference (MEPCON), 2015.

[6] A. El-Ela, R. El-Sehiemy and A. Abbas. Optimal placement and sizing of distributed generation and capacitor banks in distribution systems using water cycle algorithm. IEEE Systems Journal. 2018; 12(4):3629-3636.

[7] M. Esmaeilzadeh, I. Ahmadi and N. Ramezani. Optimal Distributed Generation Planning in Radial Distribution Networks Considering Protection Coordination Limits. Iranian Journal of Electrical \& Electronic Engineering. 2018;14 (2) : 178-187.

[8] A. Kamel, M.A. Alaam, A.M. Azmy, A.Y. Abdelaziz. Protection coordination for distribution systems in the presence of distributed generators. Electrical power components system. 2013;41(15) : 1555-1566.

[9] Supannon, Autthaporn, and Peerapol Jirapong. Recloser-fuse coordination tool for distributed generation installed capacity enhancement. InInnovative Smart Grid Technologies-Asia (ISGT ASIA), 2015 IEEE, pp. 1-6. IEEE, 2015.

[10] Short, Thomas Allen.Electric power distribution handbook. CRC press, 2014.

[11] W. El-Khattam, T.S. Sidhu. Resolving the impact of distributed renewable generation on directional overcurrent relay coordination: a case study. IET Renewable Power Generation. 2009; 3 (4): 415-425.

[12] M. Chandran, S. Ravindra kumar Dr. P. Somasundaram. Smart and adaptive overcurrent protection of distribution network with distributed generation. IJAREEIE, 2014; 3 (2).

[13] Bahador Fani, Farzad Hajimohammadi,Majid Moazzami,Mohammad Javad Morshed. An adaptive current limiting strategy to prevent fuse-recloser miscoordination in PV dominated distribution feeders. Electric Power Systems Research. 2018;157: 177-186.

[14] Reza Mohammadi Chabanlooa, Mahdi Ghotbi Maleki, S.Mohammad Mousavi Agah,Ehsan Mokhtarpour Habashi. Comprehensive coordination of radial distribution network protection in the presence of synchronous distributed generation using fault current limiter. Electrical Power and Energy Systems. 2018; 99 :214-224.

[15] Chen Li- Hsiung.Overcurrent protection for distribution feeders with renewable generation. International Journal of Electrical Power \&Energy System. 2017; 84 : 202-213.

[16] Mahamad Nabab Alam, Biswarup Das,Vinay Pant. Optimum recloser-fuse coordination for radial distribution systems in the presence of multiple distributed generations. IET Generation, Transmission \& Distribution. $2018 ; 12$ (11) : 2585-2594.

[17] Yousaf, Muhammad, and Tahir Mahmood. Protection coordination for a distribution system in the presence of distributed generation. Turkish Journal of Electrical Engineering \& Computer Sciences. 2017; 25(1): 408-421.

[18] Wafi, Jamal, et al. Applicability analysis of proactive recloser-fuse scheme for wind distributed generation into modern distribution network. 9th International Renewable Energy Congress (IREC). IEEE.2018. p. 1-6..

[19] Hossam A. Abdel-Ghany, Ahmed M. Azmy, Nagy I. Elkalashy, Essam M. Rashad. Optimizing DG penetration in distribution networks concerning protection schemes and technical impact. Electric Power Systems Research. 2015; 128: $113-122$.

[20] Y. Lu, L. Hua, J.Wu, G.Wu, G. Xu. A study on effect of dispersed generator capacity on power system protection. Proc IEEE Power Eng. Soc. Gen. Meeting. 2007: 1-6.

[21] Ahmed Abd Elbaset, Essam Abou El-Zahab, AboulFotouh A. Mohamed, Mohamed A. M. Hassan. The Penetration Level of Optimizing DG In Distribution Systems Considering Technical Impacts and Protection coordination. Twentieth International Middle East Power Systems Conference (MEPCON), 18-20 Dec. 2018.

[22] Chaitusaney, Sopit Sirisophonwattana and Surachai. Maximization of Distributed Generation with Consideration of Fuse-Recloser Coordination. The 8th Electrical Engineering! Electronics, Computer, Telecommunications and Information Technology (ECTI) Association of Thailand - Conference 2011.

[23] IEEE Standad Inverse-Time Characteristic Equations for Overcurrent Relays. IEEE Std. C37. 112.

[24] S. Chaitusaney and A. Yokoyama. Prevention of Reliability Degradation fom Recloser- Fuse Miscoordination due to Distributed Generation. IEEE Transactions on Power Delivery. 2008;23(4): 2545 - 2554.

[25] Hussain, B., Sharkh, S.M., Hussain, S., et al. An adaptive relaying scheme for fuse saving in distribution networks with distributed generation. IEEE Transaction on Power Delivery. 2013; 28(2):669-677.

[26] El-Zonkoly, A.M. Optimal placement of multi-distributed generation units including different load models using particle swarm optimisation. IET Generation, Transmission \& Distribution. 2011; 5 (7) : 760 - 771.

[27] Mirjalili Seyedali, Lewis Andrew. The Whale Optimization Algorithm. Advances in Engineering Sofware. 2016; $95,: 51-67$.

[28] D. Singh and R. Misra. Effect of load models in distributed generation planning. IEEE Transactions on Power Systems. 2007;22 (4): 2204-221.

[29] J.-H.Teng. A network topology based three phase load flow for distribution systems. Proc Natl. Sci. Counc. ROC (A). 2000;24 (4):259-264.

[30] Naiem, A.F., Hegazy, Y., Abdelaziz, A.Y., et al. A classification technique for recloser-fuse coordination in distribution systems with distributed generation. IEEE Transactions on Power Delivery. 2012; 27(1):176-185.

[31] Shah, P.H., Bhalja, B.R. New adaptive digital relaying scheme to tackle recloser-fuse miscoordination during distributed generation interconnections. IET Generation, Transmission \& Distribution. 2014, 8 (4): 682-688. 


\section{BIOGRAPHIES OF AUTHORS}

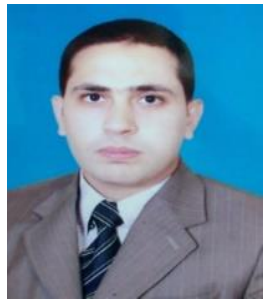

Ahmed A.Elbaset did his Bachelors in Electric Power and Machines in 2007 from ElShorouk Academy, Cairo and master degree in 2014 from Cairo university. Currently he is assistant teacher in ElShorouk Academy. He is pursuing his doctor of philosophy studies with Cairo University. His research interests are in rehabilitation of electrical distribution, distributed generation, protection coordination and renewable energy.

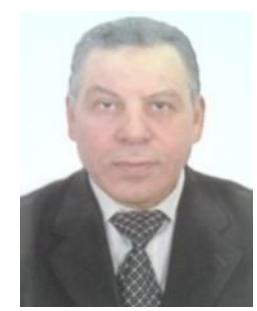

AboulFotouh A. Mohamed received his PhD 1992, in Helwan University. Presently, he is the head of electrical power and machines department, ElShorouk Academy, Cairo. His main interest is in Distribution System Design and Planning.

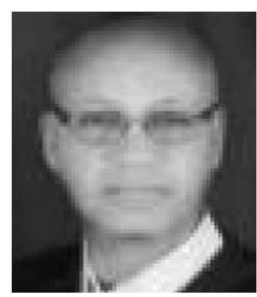

Essam El-Din Abou El-Zahab received the B.Sc. and M.Sc. degrees in electrical power and machines From Cairo University, Giza, Egypt, in 1970 and 1974, respectively, and the Ph.D. degree in electrical power from Paul Sabatier, Toulouse, France, in 1979.Currently, he is a Professor in the Department of Electrical Power and Machines at Cairo University. He was an Instructor in the Department of Electrical Power and Machines at Cairo University from1970 to 1974. His research areas include protection system, Renewable energy, and power distribution. $\mathrm{He}$ is also the author or coauthor of many referenced journal and conference papers

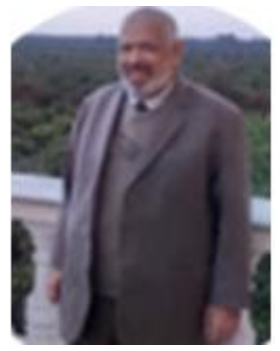

Mohamed Ahmed Moustafa Hassan is Professor (Control of Power Systems) in Electric Power Dept., Cairo University He visited many countries for practical Training during his study. Also, He was awarded a DAAD Scholarship to study for his PhD program. His research interested in implementation of Different Controllers on SMIB Control of Power Systems using different techniques SCADA for Industrial and Electric Power Systems, and WTP Intelligent PSS and LFC. Using AI Techniques in Protection Systems Using of ANFIS technique in Control and Protection systems. Modeling and control of Gas Turbines in CCPP. Modeling and control of HRSG in CCPP. Modeling and Control of Renewable Energy Particle Swarm Optimization Fractional Order PID 